\title{
What's new in steel?
}

\author{
To answer this question, Nature Materials interviewed Ohjoon Kwon, head of the research \\ laboratories of POSCO, Korea's largest steel producer, and the third-largest in the world.
}

\begin{abstract}
What is your academic background? I graduated from Seoul National University in 1972 and joined the Korean agency for defence development. I worked there for three years, and then decided to continue with my advanced degree in the US and got a fellowship from the University of Windsor in Canada. In 1981 I moved to the University of Pittsburgh, where I wanted to continue my earlier work in high-strength steels. I stayed there until 1986, when I joined POSCO as a research engineer. The head of research at POSCO came to Pittsburgh to recruit people specializing in steels and asked me to join the company.
\end{abstract}

\section{How research intensive is a company like POSCO?}

We have 352 researchers, but we are in the process of increasing our numbers up to 400 by the end of next year. In order to survive in this competitive environment, the development of new technology is essential. The portion of high-grade steel production is increasing rapidly. We are producing about 30 million tons of steel annually, half of which is high-grade. This number will increase to $75 \%$ in a few years. Nowadays, advanced highstrength steels such as TRIP and DP only make up 10-15\% of current automobiles. But in future, that portion will go up to $50-60 \%$. To produce high-quality steels you have to be very precise in controlling all the processing parameters, especially the chemical and thermal ones. The mechanical properties in particular are determined by microstructural changes during cooling - variations in the cooling pattern immediately change the properties. People say that the steel industry is very conservative. But if you look at the changes in steel products compared with 10 to 20 years ago, you find that the velocity is drastically different. In modern car models, perhaps more than half of the steels have been developed in the past five years.

What kind of research do you do? You have to consider two things. First is cost reduction, and the second is value

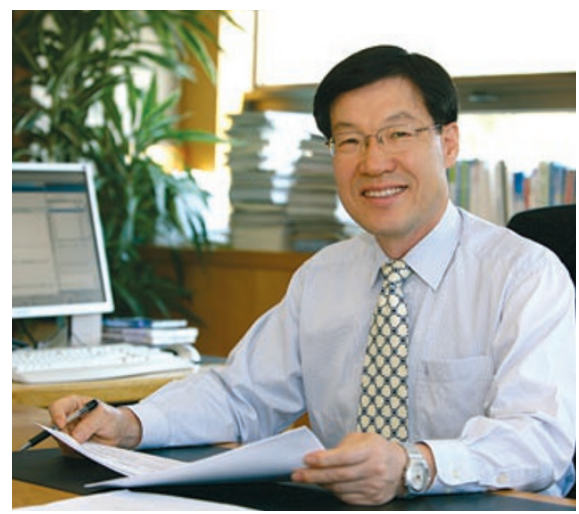

and we are asking POSTECH for new roles, concentrating more on steel or steel-related industries.

Are you happy with the quality of your graduates?

I am fairly satisfied with their performance in basic science. But if you go into engineeering areas like steel or shipbuilding, I am not so happy at all. Primarily this is due to funding policy that is pouring funds into modern technologies such as aerospace, biotechnology and nanotechnology. Not enough money is being invested into traditional industries. But these industries make most of the money for Korea.

creation. For high-grade steels you need both at the same time. Cost reduction we have to do internally by energy saving, integration of processes and productivity improvement. On the value-creation side, the fundamentals of this work are primarily done in academia, and we have strong ties with university professors around the world. Once they obtain results from basic research, we try to make use of them for the development of new steels. Also, you have to watch what is taking place in the surrounding areas. One example is nanotechnology. We are using nanotechnology to create new types of steels. For example, coating layers consisting of nanoparticles could improve high-temperature corrosion resistance, change colour with temperature, or enhance lubrication and self-cleaning.

\section{What prompted POSCO to found POSTECH in 1986?}

POSCO was a state company, whose capital came from the compensation given by Japan for the occupation of Korea in the Second World War. So we had the obligation to pay back our profits for the sake of this country and the people living in it. Having a modern education and research centre that contributes to the development of Korea was the primary motivation to found POSTECH. In addition, POSCO wanted to get new ideas from POSTECH for its business diversification. However, the demands have changed these days,
Fundamental research can be expensive. Is there sufficient support from the government?

Korea is contributing fairly significantly to pure science. What we have to take care of is the application of pure science to engineering. Also, scientists in Korea like to be isolated, like to be independent. To make advances in multidisciplinary research you have to have a system that makes scientists from different disciplines work together. I think that is the main thing the government should do. Korean universities are very conservative; they don't have much motivation to do that.

What do you think is the future of steel? Iron is the most abundant material present in the earth. In the earth's crust, iron ranks fourth in abundance after oxygen, silicon and aluminium. Iron is very stable, and is the final product of nuclear fusion/fission reactions during the Big Bang formation of the Universe. Also, it is the cheapest element - spring water is more expensive. It is a versatile and unique material. No metal expands its volume on cooling during phase transition. This unique property enables steels to cover a much wider strength range than other metals. I think iron is a special gift provided by nature, and steel is forever.

Interview by Joerg Heber 